\title{
Trajetória de Maria Yedda Linhares: notas sobre a construção de um devir
}

\section{The path of Maria Yedda Linhares: notes about self the becoming}

\author{
Carmem Silvia da Fonseca Kummer Liblik \\ carmemsfk@gmail.com \\ Doutoranda em História (Bolsista Capes) \\ Universidade Federal do Paraná \\ General Carneiro, 460, Ed. D.Pedro I, $7^{\circ}$ andar, sala 716 - Centro \\ 80060-150 - Curitiba - Paraná \\ Brasil

\section{Resumo} \\ A trajetória de vida e profissional de Maria Yedda Linhares é o tema central desse artigo. Por \\ meio da análise de entrevistas por ela concedidas, analisa-se como foi o processo da sua \\ constituição como professora universitária e historiadora brasileira. Para além do conjunto de sua \\ obra, a historiadora narra experiências pessoais e profissionais que estão articuladas, direta ou \\ indiretamente, com sua formação, atuação profissional e identidade de historiadora. O incentivo \\ de seus pais para se tornar independente financeiramente; o estímulo que recebeu em casa para \\ a leitura e reflexão; a capacidade de se relacionar com um grupo grande de intelectuais; a ampla \\ atuação em espaços institucionais e de pesquisa; o apoio e companheirismo de seu marido, José \\ Linhares, são registros que marcam sua trajetória. Escolhemos trabalhar com a perspectiva de \\ gênero como fio condutor da análise da trajetória desta historiadora, uma vez que em seus relatos \\ aparecem experiências relacionadas direta ou indiretamente a esta questão. \\ Palavras-chave \\ Maria Yedda Linhares; Gênero; Profissionalização do historiador.

\begin{abstract}
The academic career and personal life of Maria Yedda Linhares are the central themes of this article. Through the analysis of interviews granted by her, we analyzed as was the process of her constitution as a university professor and a woman Brazilian historian. In addition to the set of her work, the historian recounts personal and professional experiences that are articulated directly or indirectly, with her training, professional work and historian's personal identity. The encouragement from their parents to become financially independent; the stimulus which she had received in her family environment for reading and reflection; the ability to relate to a large group of intellectuals; the wide performance in institutional spaces and research; the support and companionship of her husband, José Linhares, are records that mark her career. We chose to work with a gender's perspective as thread of the history of this historian's analysis, since in her reports appears directly related experiences or indirectly to this issue.
\end{abstract}

Keywords

Maria Yedda Linhares; Gender; Professional historian.

Recebido em: 20/10/2016

Aprovado em: 8/12/2016 
Maria Yedda Linhares (1921-2011) faz parte de uma geração de historiadoras, assim como Alice Piffer Canabrava, Olga Pantaleão, Eulália Lahmeyer Lobo, Maria Cecília Westphalen, Marina São Paulo Vasconcellos, entre outras, chamadas de "pioneiras" (BLAY; LANG 2004). Foram as primeiras mulheres a ingressarem nos cursos superiores de História a partir da década de 1930 , coincidindo com o período em que eles foram criados e institucionalizados nas universidades brasileiras.

Em sua trajetória, Maria Yedda acumulou uma série de experiências sociais, acadêmicas e profissionais. Nas décadas de 1940 e 1950 enveredou sua pesquisa para o tema das Relações Internacionais, produzindo duas teses para o concurso de livre docência (1953) e de cátedra (1957). Nas décadas de 1970 e 1980, foi uma das pioneiras que implementou no Programa de Pós-Graduação da Universidade Federal do Rio de Janeiro (UFRJ) e da Universidade Federal Fluminense (UFF) temas voltados à História Agrária e do Abastecimento. Além disso, participou da União Nacional dos Estudantes (UNE) na década de 1940, atuou como tradutora, secretária de educação, coordenadora de Programas de Pós-Graduação e diretora da Rádio MEC. Dedicou-se mais de cinquenta anos em sala de aula, lecionando não só no Brasil, como também nos Estados Unidos e França e, conforme seus relatos, orientou mais de sessenta alunos de pós-graduação. Além de ter conquistado o título de professora emérita da Universidade Federal do Rio de Janeiro, recebeu o Prêmio Estácio de Sá do governo do estado do Rio de Janeiro. Também foi condecorada com o Palmes Académiques, a mais alta distinção acadêmica do governo da França.

Ainda em vida, em 2001, Francisco Carlos Teixeira, Hebe Maria Mattos e João Fragoso publicaram um livro intitulado Escritos sobre história e educação: homenagem à Maria Yedda Linhares. Nele, foram reunidos textos de vinte e seis historiadores e historiadoras pertencentes à geração da década de 1980 formada substancialmente por Maria Yedda. Ela não foi apenas professora e orientadora desses profissionais, como também foi amiga e conselheira em diversas ocasiões. Maria Yedda, como afirmam os organizadores da coletânea, é uma das mestras na profissionalização do ofício de historiador no Brasil, cabendo a ela um papel decisivo na criação da jovem historiografia brasileira (SILVA; MATTOS; FRAGOSO 2001, p. 14).

Na trajetória de vida e profissional de Maria Yedda, portanto, pretendemos analisar os traços, sinais e situações que podem nos indicar como foi o processo da sua constituição como historiadora para além do resultado final de seu trabalho, ou seja, de sua obra e repercussões no interior do campo historiográfico. É irrefutável que a qualidade e o valor conferidos às suas obras são registros importantes e que, sem eles, não existe a possibilidade de relacioná-las ou incluí-las ao campo historiográfico. Mas a obra não é somente um produto que se realiza em si a partir de uma mente superior, diferenciada ou genial. Entendemos a obra como resultado final de um processo amplo no qual as dimensões da vida pública e privada se misturam, em que os aspectos subjetivos espelhados por redes de afetos e desejos movem estes agentes para o campo da pesquisa histórica, em que a identidade do historiador e da historiadora faz parte de um 
devir sempre em composição conforme os contextos sócio-históricos, pessoais e institucionais.

\section{Educação diferenciada e a opção pela História}

As origens sociais e familiares de Maria Yedda aparecem com muita frequência em suas entrevistas e depoimentos, bem como os detalhes das experiências de vida de seus pais. O sentimento de pertencimento a uma história familiar única e singular é acompanhado pela tomada de consciência e valorização da influência materna e paterna em sua vida. Se analisarmos sua história de vida quando jovem pelo viés biográfico, é impossível deixar de perceber a temática da genealogia. Ou seja, nenhuma posição de enunciação advém ingenuamente no espaço em que narra suas memórias: o desafio é justamente achar uma voz autobiográfica que possa dar sentido a um mito de origem, a uma genealogia, a um devir predestinado. Por isso, como sugere Leonor Arfuch, o espaço biográfico - a narração de histórias e experiências, a captação de vivências e lembranças opera, completamente, no reconhecimento do próprio local de origem (ARFUCH 2010, p. 60). E, por extensão, Benito Schmidt também chama atenção para o fato de que em muitos trabalhos biográficos, é possível perceber que os autores buscam na infância e/ou na adolescência uma espécie de predestinação para suas atividades futuras (SCHMIDT 2000, p. 58).

De modo geral, Maria Yedda chama atenção em suas entrevistas que desfrutou um ambiente familiar que estimulava a leitura, os debates e a busca

118 do conhecimento. Outro registro importante que aparece em sua narrativa é o incentivo que recebeu dos pais para buscar a independência financeira e autonomia intelectual, algo raro na educação feminina nas primeiras décadas do século XX. Podemos assinalar que as experiências de vida pelas quais ela passou na juventude, sobretudo aquelas relacionadas às interações sócio-familiares, impactaram sua futura jornada no meio acadêmico.

Certamente Maria Yedda recebeu uma educação diferenciada do ponto de vista do gênero. Como se sabe, essa historiadora nasceu na década de 1920, pertencendo a uma geração que atribuía às mulheres o papel de esposa, mãe e dona de casa, ocupações consideradas como o destino natural das mulheres. Maternidade, casamento e dedicação ao lar faziam parte da essência feminina, sem que houvesse muitas possibilidades de aberturas para espaços de resistência e contestação (PINSKY 2012). A vocação voltada para a maternidade e a vida doméstica seriam marcas de feminilidade, enquanto a iniciativa, a participação no mercado de trabalho, a presença no espaço público, a força e o espírito de aventura definiriam a masculinidade. A religião tinha um papel muito importante na vida das mulheres, reforçando e conferindo a elas seus lugares sociais permeados por um controle moral e sexual. Isso não quer dizer que todas as mulheres pensassem e agissem de acordo com o esperado - como é o caso de Maria Yedda e outras pioneiras - mas que as expectativas sociais faziam parte de sua realidade, influenciando suas atitudes e moderando suas escolhas. Por outro lado, sobre as diversas maneiras de expressarem suas subjetividades, é possível sugerir que Maria Yedda teve, com a mediação de sua própria mãe, 
experiências diferenciadas na juventude, desviando-se - dentro de alguns limites - das exigências sociais impostas.

Quanto à educação, a mãe de Maria Yedda nunca permitiu que ela estudasse em colégios particulares de Fortaleza, principalmente aqueles dirigidos por religiosas. Preferiu que a filha recebesse instruções em casa, perto da família, justamente porque as "freiras só serviam para educar meninas ricas". Foi dessa maneira que Maria Yedda aprendeu a ler e escrever com a ajuda de uma professora que ia até sua casa. A infância em Fortaleza foi marcada por muita música, dança, teatro e cinema. Costumava levar uma cadeira para assistir aos filmes que passavam no Grêmio Recreativo do Calçamento Mecejana, lembrando muito as cenas do famoso filme Cinema Paradiso. Apesar de nunca ter assistido peças de teatro, quando criança gostava de escrever roteiros que eram dirigidos e encenados por ela mesma e um grupo de amigas. De cabelos curtos e com franjinha, Maria Yedda "cantava, dançava, declamava, era muito metida, muito saliente, muito apresentada" (LINHARES 1992, p. 217). A historiadora afirma que era uma criança destemida e desinibida, cujo perfil se diferenciava dos modelos subjetivos femininos da época, em que as mulheres deveriam ser discretas, modestas, inibidas e pouco atuantes no espaço público.

A partir de 1929, as dificuldades econômicas que atingiram a família, principalmente o desemprego do pai, motivaram sua mudança para o Rio Grande do Sul. No entanto, a permanência da família neste estado foi restrita ao período de oito meses, uma vez que todos seguiram para o Rio de Janeiro, onde se estabeleceram definitivamente em 1933 e, como diz Maria Yedda "cessa nesse ponto o relato da família nordestina migrante". Um dos problemas que ela enfrentou no transcurso dessas mudanças interestaduais foi a interrupção dos estudos. Até os 12 anos de idade, ela não tinha ainda completado a educação formal na escola primária. Mas perto da casa onde passaram a morar, na Tijuca, havia um instituto escolar chamado Lafayette. Foi nele que Maria Yedda se preparou para o exame de admissão no ginásio, iniciando posteriormente, o ensino secundário. Concluiu o ensino no Colégio São Paulo, onde muitas de suas amigas do Ceará estudavam também. "Aí mamãe brigou comigo, porque era colégio de freiras. Ela nunca botou o pé lá. Mas foi lá que terminei o ginásio" (LINHARES 1992, p. 218).

Quando estava no último ano do ginásio, em 1938, o Ministério da Educação promoveu um concurso intelectual - a Maratona Intelectual em História, Matemática e Português - no qual os colégios de todo o país podiam inscrever os alunos do ensino secundário. Contudo, as freiras do colégio não queriam inscrever Maria Yedda no concurso, uma vez que ela poderia "desmoralizar o colégio" por presidir a comissão do baile de formatura e por gostar de dançar: "[...] as freiras estavam com muita raiva de mim porque achavam que dançar era imoral" (LINHARES 1992, p. 218). Mesmo assim, Maria Yedda foi sozinha ao Ministério, explicou a situação que ocorria no colégio e solicitou sua inscrição. Tendo conseguido participar da maratona, ela realizou durante um mês as provas escritas e debateu diversos assuntos com outros alunos - quem competiu com ela, por exemplo, foi Darcy Ribeiro. E o resultado? 
Depois de um mês de provas, uma animação danada, cheguei em casa com mamãe, voltando de um concerto no Municipal, e lá estava um telegrama com a notícia: eu havia tirado o primeiro prêmio nacional na maratona de história. Tive dez em tudo (LINHARES 1992, p. 219).

Um dos prêmios conquistados nesta maratona foi o livro A História Geral, de Varnhagen. Foi exatamente nessa época, em meados da década de 30, que surgiu o interesse pela História. Na verdade, Maria Yedda não tinha ainda uma noção clara do que era propriamente a formação em conhecimento histórico. Em um primeiro momento, a necessidade de trabalhar constituiu um dos principais motivos para o ingresso em um curso superior. "Estaria mentido se dissesse que foi por idealismo. Eu era uma moça pobre e precisava trabalhar. Na década de 30, o que uma moça de classe média sem recursos poderia fazer?". O objetivo era se formar para depois se tornar professora em escola pública, apesar de que ela nunca sentiu vocação para trabalhar com crianças. Tampouco passou pela sua cabeça cursar Medicina, Engenharia ou Direito. Sua sorte foi a fundação da Universidade do Distrito Federal (UDF) pelo secretário da Educação, Anísio Teixeira, cujo projeto congregava cursos da área de Letras, Ciências Sociais, Ciências Físicas e Matemática. Em janeiro de 1939, aos 17 anos, Maria Yedda se matriculou no curso de História depois de ter passado no exame vestibular. "Era muito jovem diante dos colegas bem mais velhos e experientes no magistério, muitos formados nas faculdades tradicionais" (LINHARES 2007, p. 25).

\section{Clio nas relações acadêmicas, profissionais e afetivas}

Na extinta UDF, Maria Yedda narra que teve aulas com Francis Ruellan, Victor Tapié e Antoine Bon. Os professores que mais marcaram foram aqueles que apresentavam ampla erudição e capacidade analítica, ao passo que as críticas convergiam àqueles que davam aulas "tradicionais", "superficiais" e "positivistas". Vale destacar que a passagem de Maria Yedda na UDF foi breve, uma vez que ela ganhou uma bolsa (1940-1942) do Institute of International Education, em Nova York, quando estava cursando o segundo ano do curso de História. Nos Estados Unidos, Maria Yedda teve experiências muito enriquecedoras do ponto de vista social e acadêmico. Ela narra que conheceu os costumes do país, aprendeu "seu cancioneiro, sua culinária" e era sempre convidada para passar feriados e fins de semana na residência das famílias de suas colegas. Frequentava festas, jogos esportivos, teatros, cinemas, além de ter ministrado um curso de Português no centro de línguas estrangeiras em Middlebury, Vermont. Do ponto de vista das descobertas intelectuais, foi nos Estados Unidos que ela teve contato, pela primeira vez, com temas voltados às relações raciais, escravidão, mundo agrário e história demográfica e econômica.

Vale ressaltar o que significava a experiência de viagens para as mulheres nascidas no início do século. Nas décadas de 1930 a 1960, uma mulher que viajasse a trabalho, sozinha ou com amigos, possivelmente não era bemvista em um primeiro momento. Não só Maria Yedda, mas praticamente todas 
as historiadoras da primeira geração ${ }^{1}$ que fizeram carreira na universidade viajaram, frequentaram arquivos, bibliotecas e espaços institucionais em que, até o momento, prevalecia somente a presença de homens. Somadas às experiências docentes, um registro notadamente importante na carreira de Maria Yedda e dos historiadores e historiadoras da primeira geração, diz respeito às numerosas viagens a trabalho que fizeram, sobretudo ao exterior. Ao deixar o país, a historiadora teve experiências que decididamente impactaram não apenas em sua carreira, como também nas relações sociais e familiares. As viagens realizadas, a autonomia de programar as atividades, os contatos com docentes e alunos de instituições estrangeiras, e os diversos tipos de trabalho assumidos são indícios muito significativos que podem ser pensados à luz do conceito "sair" da historiadora Michelle Perrot. São mulheres que saíram fisicamente, realizando viagens, como também "saíram moralmente", recusando os papéis que lhe eram atribuídos e buscando inserção e reconhecimento no mundo do trabalho (PERROT 2005).

Maria Yedda retornou dos Estados Unidos em 1942, a pedido de seu pai, pois a família passava por dificuldades financeiras e era preciso que trabalhasse para ajudar nas despesas domésticas. Passou a ensinar português para estrangeiros a fim de complementar a renda familiar e posteriormente trabalhou no DASP (Departamento Administrativo do Setor Público) como "técnica de pessoal". Após o retorno, foi transferida para a Faculdade Nacional de Filosofia (FNFi), sendo integrada à turma de Eulália Maria Lobo.

Um dos traços marcantes em sua trajetória acadêmica foi, desde cedo, sua inserção em espaços de sociabilidade. Ainda na época em que era estudante universitária, conheceu "toda uma juventude intelectual e politizada". Tornouse amiga de Samuel Wainer, Paulo Silveira, Joel Silveira, Carlos Drummond de Andrade, Sérgio Buarque de Holanda e Hermes Lima. Em reuniões estudantis, travou contato com Mario Alves e Carlos Marighela. Outro grande amigo seu foi Darcy Ribeiro, cuja amizade iniciou-se em 1942. Foram cinquenta anos de amizade e juntos "elaboraram a Universidade de Brasília, que foi o grande momento de união de cérebros da universidade brasileira". Outra pessoa que a influenciou na maneira de pensar a política no Brasil foi Gabriel Lacombe, diretor francês da agência Reuters e fundador da France Presse no Brasil.

Maria Yedda diplomou-se em História em 1944 e o acontecimento mais importante veio alguns anos mais tarde, em 1946, com o convite para ser assistente do professor Carlos Delgado de Carvalho, mestre de origem francesa e catedrático de História Moderna e Contemporânea. Como na época não havia concursos ou processos similares, os convites se davam conforme as relações de amizade entre catedrático e aluno. Maria Yedda conhecia bem

\footnotetext{
1 Apesar de Maria Yedda formar-se no Rio de Janeiro, para se compreender as gerações de historiadores apoio-me na reconstituição das linhagens historiográficas propostas por Capelato, Glezer e Ferlini (1994). Elas evidenciaram três momentos distintos na escola uspiana de história - a USP teve papel fundamental na formação de outros cursos de História, especialmente os das regiões Sul e Sudeste. Temos os historiadores uspianos, chamados de "formadores"; em seguida os historiadores da primeira geração, orientados pelos formadores; e por último os historiadores da segunda geração, orientados por alguns formadores, mas principalmente pelos doutores da primeira geração (CAPELATO; GLEZER; FERLINI 1994, p. 350).
} 
Carlos Delgado, "por relações de família"2 e já tinha colaborado com ele na realização de dois livros. Sua aproximação com a cadeira História Moderna e Contemporânea alimentou, pioneiramente, seus estudos referentes à História das Relações Internacionais. ${ }^{3}$

O estudo das questões internacionais iniciou-se quando a UDF foi institucionalizada por Anísio Teixeira. Percebeu-se, em meio às turbulências da década de 1930 que o país estava vinculado às grandes transformações mundiais. Delgado de Carvalho, além de historiador, também possuía vivência diplomática e, além de implementar seminários, trouxe estudos sobre a Questão do Oriente, as rivalidades europeias, a ação do Imperialismo, e especialmente as rivalidades entre as potências em torno da dominação da África. Maria Yedda Linhares, em torno de quem se reunia um jovem grupo de pesquisadores Hugo e Arthur Weiss, Francisco Falcon, Valentina Rocha Lima e, mais tarde, Ciro Flamarion Cardoso, José Luiza Werneck da Silva e Pedro Celso Uchoa Cavalcanti - aprofundaria tais análises, em especial em torno da questão do Imperialismo e da Descolonização (SILVA; MATTOS; FRAGOSO 2001, p. 11).

Apesar das dificuldades iniciais, Maria Yedda foi uma das precursoras nos estudos das Relações Internacionais e contou com alguns contratempos a serem superados no tocante à realização de sua pesquisa. Ela possuía uma documentação razoável sobre o Egito e política inglesa no Oriente Próximo, mas não o suficiente para o desenvolvimento de uma pesquisa. Narra que nos anos 1950 não havia no Brasil um sistema ou uma instituição que estimulasse a ida de 122 pesquisadores ao exterior. Foram necessárias duas décadas para que a estrutura de um sistema de pesquisa em História se organizasse institucionalmente, algo que ocorreu somente no início da década de 1970, com a Reforma Universitária. ${ }^{4}$ Maria Yedda buscou uma solução ao organizar uma biblioteca em sua residência, consolidada com seus próprios recursos:

$\mathrm{Na}$ realidade, procurei com meus próprios recursos organizar uma verdadeira biblioteca de pesquisa em minha residência, cerca de 800 volumes de documentação relativa às Relações Internacionais, às políticas do Imperialismo, documentação essa de origem francesa, alemã, italiana, austríaca e inglesa. Através do France Presse, recebia regularmente os artigos dos jornalistas sediados no centro das grandes questões internacionais e suas crises. Na medida do possível, estou segura de que fiz um trabalho sério e o único possível naquela conjuntura (LINHARES 2007, p. 29).

\footnotetext{
${ }^{2}$ A esposa de Delgado de Carvalho, dona Vera, era tia de uma grande amiga de Maria Yedda, Cecília Wagley. 3 Por meio de sua amizade com o diretor da Reuters e France Presse, Gabriel Lacombe, Maria Yedda teve acesso a muitos documentos internacionais. Aos poucos, ela passou a encomendar documentos diplomáticos da Alemanha, Áustria, Itália, Inglaterra e França. Por causa disso, foi convidada para ensinar História das Relações Internacionais no Instituto Rio Branco.

${ }^{4}$ Além da militância política, os primeiros anos da década de 1960 foram marcados por um intenso movimento visando as mudanças do sistema universitário brasileiro, do qual participaram os docentes, os pesquisadores e o movimento estudantil no projeto que iriam resultar na Reforma Universitária. Entre as medidas propostas pela Reforma, com o intuito de aumentar a eficiência e a produtividade da universidade, sobressaem: o sistema departamental, o vestibular unificado, o ciclo básico, o sistema de créditos e o fim do sistema seriado, a extinção das cátedras, a matrícula por disciplina, a carreira do magistério no ensino superior e a criação de cursos de pós-graduação (FÁVERO 2006; FERREIRA 2013).
} 
Obviamente que as dificuldades de pesquisa não foram enfrentadas somente por esta historiadora, mas sim por todas as pessoas que fizeram parte da primeira geração de historiadores brasileiros. Tiveram eles que decidir, estruturar e organizar como o trabalho historiográfico deveria ser feito. Uma das primeiras medidas a serem tomadas era a compilação de referências bibliográficas atualizadas e relevantes para o estudo da história. Muitos historiadores e historiadoras criaram com seus próprios recursos vastas bibliotecas particulares, cujos livros não podiam ser encontrados nas bibliotecas das universidades. Com bibliotecas prontas em suas residências, era normal e frequente a visita de colegas da profissão, alunos e alunas para a consulta, empréstimos e, porque não, um café. Assim se organizaram os elementos que constituiriam inicialmente o "ofício do historiador" no Brasil, baseados numa forte rede de sociabilidades de historiadores e historiadoras, e demais intelectuais das ciências humanas para além dos espaços universitários.

Naquela época, um dos objetivos mais caros era a elaboração de um método de trabalho, especialmente que valorizasse a análise de fontes primárias e o debate crítico da bibliografia. Para isso se tornar possível, foi necessária a constituição de um perfil acadêmico e intelectual voltado para a pesquisa em grupo. O individualismo precisaria ser substituído, como afirma Maria Yedda, pelo "espírito coletivo", em que os encontros e reuniões marcaram as experiências acadêmicas desses intelectuais. Em muitos casos, as reuniões não eram formais e não ocorriam nos gabinetes ou salas da universidade. Os encontros ocorriam nas residências dos intelectuais, restaurantes e bares:

Era muito comum eu e meu marido pegarmos um avião na quinta-feira e irmos até lá. Encontrávamos com Novais, Alice Canabrava, Octávio Ianni, Fernando Henrique Cardoso, tomávamos um chope ou jantávamos, e no dia seguinte eu ia às livrarias. Era muito importante esse convívio, fazia parte da nossa prática. Vivíamos sonhando aqui em pesquisar como eles (LINHARES 1992, p. 229).

Maria Yedda não foi a única historiadora que estabeleceu e se inseriu em redes de sociabilidade com intelectuais das ciências humanas. Conforme entrevistas e depoimentos de Alice Canabrava, Eulália Maria Lobo, Maria Cecília Westphalen, Olga Pantaleão, entre tantas outras, os contatos e laços filiais com colegas de profissão foram de grande importância na constituição de suas carreiras. Por essas razões, sugerimos que a amizade foi um dos fatores que serviu como alicerce para as mulheres da primeira geração se tornarem historiadoras. Através dela, as profisisonais da história construíram redes de relações que lhes davam suporte para confrontar a comum hostilidade à intelectualidade feminina. ${ }^{5}$

\footnotetext{
${ }^{5} \mathrm{~A}$ hostilidade à intelectualidade feminina pode ser compreendida a partir de sua genealogia filosófica. Kant e Hegel, filósofos em cujas orientações a maioria dos historiadores europeus e americanos se basearam (nem que seja de modo derivativo), tinham gastos longos capítulos de suas obras descrevendo que estados subjetivos eram femininos. Para Kant, apenas os homens podiam operar moralmente de acordo com o princípio do imperativo categórico, e apenas eles poderiam ter de forma plena a razão inata para relacionarse com o que estava fora de compreensão - isto é, da natureza - e assim desenvolver o conhecimento. Kant colocou as atividades das mulheres no reino da nutrição, da emoção, da sensibilidade e da cultura. Um platô nessa linha divisória surgiu com Hegel, cuja dialética bifurcou o mundo em um sujeito e um objeto
} 
Beatriz Polidori Zechlinski, em sua pesquisa intitulada Três autoras francesas e a cultura escrita no século XVII: gênero e sociabilidades, exemplifica como os homens letrados ofereceram apoio intelectual e afetivo nos diversos momentos em que a autoridade literária de algumas escritoras foi questionada. Eles deram apoio e auxílio para as iniciantes, compartilhando com elas a experiência de superar os desafios de praticar uma atividade que era não só desaconselhada para as mulheres, mas considerada um desvio da sua verdadeira função social. Analisando algumas relações de amizade entre homens e mulheres do século XVII, Zechlinski verifica que existiram relacionamentos que não eram dicotômicos nem marcados pela oposição. Portanto, eram experiências nãohierárquicas de troca intelectual nas quais se desenvolveu a afetividade entre homens e mulheres, retirando-as do patamar da subordinação (ZECHLINSKI 2012, p. 114-115). A amizade mostrava-se tanto para as escritoras estudadas por Zechlinski quanto para as historiadoras da primeira geração, não só como uma tática de inserção nos espaços do saber, mas também como uma experiência de igualdade que Ihes proporcionava desenvolver relações com homens em esferas da vida social que perpassassem o âmbito familiar e doméstico.

\section{Desafios da profissão, pesquisa e o "ser historiadora"}

Um dos acontecimentos que merece destaque na trajetória de Maria Yedda foi a conquista da cátedra. Contudo, como veremos a seguir, ela oferece sua própria visão sobre o que significava a Cadeira no contexto do ofício do historiador. Inicialmente, narra que apenas dois concursos davam acesso ao cargo de professor: concurso de livre-docência e de cátedra. Maria Yedda realizou provas para a livre-docência em 1953 e para a cátedra em História Moderna e Contemporânea em 1955, algo inusitado na década de 1950. Primeiro, porque era uma mulher fazendo concurso para a cátedra; segundo, era muito jovem e a cátedra significa o topo da carreira acadêmica; terceiro, concorreu em uma área que não tinha ainda tradição no Brasil - História Moderna e Contemporânea.

Sobre o processo da conquista da cátedra, a historiadora afirma que esse não era seu objetivo profissional, pois sentia-se despreparada, mas aceitou o desafio - foi convidada pelo professor Delgado de Carvalho para ser sua sucessora - e elaborou um tema que se gostava, qual seja: As relações anglo-egípcias e o Sudão (março, 1950-novembro, 1951). Além da tese, deveria ministrar duas aulas para uma banca com cinco examinadores, cujos temas costumavam ser sorteados. Sobre esse processo, lembra-se que não se sentia segura para enfrentar um concurso assim:

Fui praticamente forçada a me inscrever na livre-docência por parte do meu catedrático que deveria se aposentar por limite de idade. Seu sucessor seria Antero Manhães, mas ele morreu subitamente e a cadeira

nitidamente opostos: senhor e escravo, masculino e feminino, duas partes mutuamente antagônicas. O sujeito soberano masculino lutava por supremacia, conhecimento e controle do objeto feminizado. Bonnie Smith sugere que, para os historiadores, essa realidade objetiva era encontrada em arquivos, fatos e nas informações analisadas. No caso das historiadoras profissionais dos Estados Unidos e de alguns países europeus, Smith indaga: "onde se posicionava a mulher profissional em um retrato de trabalho científico tão determinado pelo gênero"? (SMITH 2003, p. 392). 
ficou sem um sucessor natural. Eu não queria, pois era muito jovem, com filhos pequenos e me sentia despreparada. No entanto, com apoio de meu marido e dos meus alunos, aceitei o desafio (LINHARES 2007, p. 32).

Maria Yedda tinha 36 anos de idade quando prestou este concurso, recordando-se que recebeu apoio fundamental de seu marido, José Linhares, e de Francisco Falcon, que era assistente da cadeira e que a ajudou com a leitura da bibliografia. Eles dividiam as leituras e todas as noites, às vinte e três horas, ela telefonava para que ele passasse os resumos que tinha lido. "Só consegui dar conta porque tive ajuda inestimável daqueles que já trabalhavam comigo, sobretudo de Francisco Falcon, que foi realmente formidável" (LINHARES 1992, p. 225). Menciona ainda que não era comum a presença de mulheres no regime da cátedra e que foi a primeira a ocupar este posto na FNFi, em 1955:

Foi um concurso muito importante, pois não era comum a mulher chegar ao posto de catedrática. Creio que fui cronologicamente a primeira na área científica. Esse processo todo me exauriu e passei a enfrentar ciumadas dos colegas" (LINHARES 2007, p. 32).

$\mathrm{Na} F N F i$, os catedráticos da História eram vistos como resistentes ao coleguismo e à cooperação. Dedicavam-se a relacionamentos com poucos alunos, apadrinhavam seus sucessores, e autodefiniam-se como os únicos conhecedores de suas disciplinas. Quando foi extinta a cátedra, em 1967, Maria Yedda chegou a dizer a Hélio Vianna: "Dr. Hélio Vianna, acabou a cátedra. O senhor não manda mais na História do Brasil". Para ela, a "velha Filosofia" teve catedráticos brilhantes, como José Carlos Lisboa (Literatura Espanhola), Anísio Teixeira (Educação), Victor Nunes Leal (Ciências Políticas), Arthur Ramos (Antropologia), Josué de Castro (Geografia Humana), Thiers Moreira (Literatura Portuguesa) e Alvim Correa (Literatura Francesa). Mas, "parece que à História, os deuses do Olimpo não reservaram um final feliz, como uma sina, um destino implacável" (LINHARES 2007, p. 29).

Nesse caso, Maria Yedda refere-se especificamente ao historiador Eremildo Luiz Vianna. Ocupando a cadeira de História Antiga e Medieval, Eremildo não deixou boas memórias para ela, e praticamente em toda a primeira geração de historiadores da FNFi. Ele foi o responsável por denunciar aos órgãos de segurança da ditadura militar os professores de História da FNFi que mantinham posições políticas antagônicas à ditadura. Além dele, "havia o Helio Vianna, que considerava seu livro como a revelação da própria História" (LINHARES 2007, p. 29). A única exceção, como já dissemos anteriormente, era o professor Carlos Delgado de Carvalho, que a convidou para sucedê-lo na cadeira de História Moderna e Contemporânea.

Maria Yedda destacou-se não somente como professora e pesquisadora, mas também pelo comprometimento com os embates políticos e ideológicos da época. Além de se preocupar com a Reforma Universitária, ela passou por experiências conflitantes e traumáticas após o golpe de 1964. A universidade, naqueles anos de ditadura, tornara-se muito visada, particularmente o Instituto 
de Filosofia e Ciências Sociais (IFSC). ${ }^{6}$ Várias denúncias a professores e professoras foram feitas, as quais apontavam para a existência de uma célula comunista no Instituto. Conforme seus relatos, as denúncias foram feitas por Eremildo Viana e os "conspiradores" entregues à polícia. Por ter participado de muitos movimentos contra a ditadura, chegou a responder, entre 1964 e 1966, a sete inquéritos políticos militares (IPMs). Foi presa três vezes e, assim como outros professores, aposentou-se compulsoriamente em 1968 quando já era professora titular de História Moderna e Contemporânea da UFRJ. Conforme seu depoimento, dois registros de sua vida privada e pública foram prejudicados: o pessoal e familiar, bem como a profissão de historiadora e professora, uma vez que perdeu o direito de trabalhar.

Foi um período extremamente difícil de vida, para mim e para meu marido, filhos e meus pais, face às infâmias levantadas contra mim, movidas por inveja profissional. É profundamente lamentável que interesses mesquinhos fossem acobertados por instituições do Estado brasileiro. Foi-me negado o exercício de minha profissão no meu próprio país, por mim conquistada em concursos públicos de título, provas e teses em bancas oficiais. Negavam-me a subsistência e o direito de trabalhar (LINHARES 2008, p. 15).

Nesse momento, a cadeira de História Moderna e Contemporânea foi desmembrada em disciplinas autônomas, descoordenadas e sem pessoal com formação adequada para ministrá-las. ${ }^{7}$ Maria Yedda recebeu convite de colegas franceses, entre os quais Fernand Braudel, Fréderic Mauro e Jacques Godechot para se estabelecer na França, de modo que passou cinco anos residindo nesse país, de 1969 a 1974. No primeiro ano, deu aula em Vincennes, por intermédio de Josué de Castro e logo depois foi nomeada professora titular em Toulouse. Conta ela que nessa "fase francesa", foi muito importante o convívio com Ciro Cardoso, que estava fazendo doutorado lá. Fernand Braudel chegou a mandar dois telegramas para o Presidente Costa e Silva, pedindo que fosse autorizada sua saída da França e o retorno ao Brasil. O pedido foi autorizado e Maria Yedda retornou assim que soube que seria avó: "Voltei quando minha neta nasceu, voltei para ser avó" (LINHARES 1992, p. 239).

Maria Yedda retornou ao Brasil em 1974 e, aposentada pelo AI-5, estava proibida de atuar na universidade. Encontrou resistência por parte do setor privado para trabalhar e foi impedida de assinar as traduções que fazia. Foi somente em 1976 que retornou às atividades acadêmicas, ao ser convidada por um grupo de jovens economistas e cientistas sociais para participar de um Seminário sobre Desenvolvimento Agrícola organizado pela Fundação Getúlio Vargas (FGV). A intenção desse seminário era apresentar um extenso levantamento de fontes, suscitar novas questões e diversificar abordagens metodológicas. Apesar de ser uma estudiosa das Relações Internacionais, Maria Yedda aceitou o desafio e escreveu uma comunicação sobre o uso da História Quantitativa na História da

\footnotetext{
${ }^{6}$ A Faculdade Nacional de Filosofia (FNFi) foi dividida em escolas e institutos. Foi criado, então, o Instituto de Filosofia e Ciências Sociais (IFSC).

${ }^{7}$ Até 1994 a UFRJ ficará sem um professor ou professora titular de História Moderna e Contemporânea.
} 
Agricultura Brasileira. Dois meses depois do evento, recebeu um convite para estruturar um programa de pesquisa sobre a Agricultura Brasileira, passando a trabalhar no Centro de Pós-Graduação em Desenvolvimento Agrícola (CPDA) da FGV. ${ }^{8}$ Nele, foi pesquisadora, professora do Mestrado que se inaugurava, e diretora do Programa. Nessa experiência, contou com o apoio fundamental de Ciro Cardoso - que contribuiu com pesquisas relacionadas ao tema da escravidão, e Francisco Carlos Teixeira da Silva, com os quais iniciou uma longa e duradoura parceria intelectual e de amizade.

Na década de 1970, começava a se fortalecer a convicção de que a busca de fontes oficiais (mantidas em arquivos centralizados) e não oficiais seria fundamental para diversificar as interpretações da história brasileira e gerar novos campos de pesquisa. No Rio de Janeiro, Maria Yedda liderou o grupo de pesquisadores responsáveis pelas histórias agrárias no contexto da economia colonial brasileira. Amigos, colegas de profissão e ex-alunos, tanto do Rio de Janeiro quanto de São Paulo, desenvolveram seus trabalhos e os expuseram nos salões da antiga residência da monarquia no Horto Florestal do Rio de Janeiro. Entre eles estavam Maria Luiza Marcílio, Ester Boserup, Katia Queiroz Mattoso, Francisco Iglésias, Alcir Lenharo, Ciro Cardoso, Alice Canabrava, Francisco Falcon, Manoel Mauricio, Warren Dean, Barbara Levy, Ismênia de Lima Martins, Afranio Garcia, entre tantos outros. As marcas do grupo formado no Rio de Janeiro foram a grande produtividade acadêmica, a adoção de um método específico de pesquisa e a influência da história regional francesa. São dissertações e teses produzidas nos programas de pós-graduação da UFF e da UFRJ condizentes com a terceira geração de historiadores que se dedicaram a esse tema, sob a liderança de Maria Yedda.

A partir desse contexto, Maria Yedda e Teixeira da Silva produziram duas obras de grande importância para a historiografia brasileira, quais sejam: História do abastecimento: uma problemática em questão (1530-1918) (1979) e História política do abastecimento. Além de privilegiarem diferentes recortes espaçotemporais, nesses dois livros, os autores defendem uma abordagem metodológica que contempla diversos fatores para se compreender a história do abastecimento, como por exemplo, os transportes, o consumo, a renda gerada, os hábitos e as técnicas de cultivo, a organização fundiária, os hábitos alimentares, o consumo urbano etc. A ideia central não era fazer uma síntese da história do abastecimento, e sim "situar, historicamente, o problema do abastecimento".

Dois anos depois da publicação dessas obras, Maria Yedda e Teixeira da Silva avançam o entendimento das questões do abastecimento no contexto da economia colonial. Em História agrária brasileira: combates e controvérsias (1981), os autores analisam o elemento camponês no Brasil e a produção de subsistência, cujos temas eram ignorados pelos estudos historiográficos. Assim como a temática do abastecimento, o trabalho do camponês também começa a ser problematizado na década de 1970 conforme os estudos de Jacob Gorender, Ciro Flamarion Cardoso e Maria Isaura Pereira de Queiroz. Apesar de não concordarem

${ }^{8}$ O CPDA foi incorporado no início da década de 1980 à Universidade Rural do Rio de Janeiro (UFRRJ). 
em muitos pontos de análise, esses autores têm como ponto em comum a percepção de um Brasil em suas especificidades sociais e econômicas que não podem ser compreendidas numa grande síntese. Maria Yedda e Teixeira da Silva chamam a atenção para a análise da dinâmica da produção de subsistência, considerando o uso e a posse da terra, os regimes agrários, as hierarquias sociais, os movimentos demográficos e os sistemas de cultivo.

Com o processo de redemocratização, Maria Yedda foi anistiada em 1979 e em 1980 reintegrada à UFRJ. Contudo, ainda precisou travar uma grande batalha para obter o regime de tempo integral e dedicação exclusiva, o que ocorreu somente perto de se aposentar, em 1991. Foi também professora da Universidade Federal Fluminense e, junto com Ciro Flamarion Cardoso e Francisco Falcon, implantaram a Pós-Graduação de História daquela universidade. Continuava empreendendo esforços por mudanças na formação dos estudantes, docentes e nos Programas de História do Brasil. Defendia que estes programas deviam levar em consideração as realidades locais. No início da década de 1980, recebeu convite para ser Secretária Municipal e Estadual de Educação do Rio de Janeiro nas duas gestões do governador Leonel Brizola (1983/1987 e 1991/1994), como também na primeira gestão do prefeito Marcelo Alencar (1983 a 1986). Nestas gestões, junto com Darcy Ribeiro, implantaram os Centros Integrados de Educação Pública (CIEPS).

Tão importante quanto tudo o que aqui foi discutido, as formas mais amplas possíveis de engajamento político que despontavam já seriam o termômetro do 128 quanto essa historiadora não era ingênua nem despojada de desejos intelectuais, acadêmicos e de transformação social. Pelo contrário, tinha posicionamentos políticos sobre os problemas brasileiros bem como a sua abrangência. Maria Yedda e tantas outras mulheres historiadoras da primeira geração, não foram apenas docentes e pesquisadoras em História distanciadas das realidades do seu país, mas sim mulheres que interpretavam as condições sociais, políticas e econômicas e desejavam mudanças por meio da participação política. "Mas é que aquele momento, torno a insistir, nós estávamos muito ligados ao país, ao social, à ideia de mudança. Em síntese, nós éramos politizados. Talvez nem soubéssemos disso, mas hoje é possível ver" (LINHARES 2007, p. 232). Para ela, o historiador profissional não pode se dedicar apenas aos "papéis velhos", mas precisa ter também experiências diversas, ou como ela prefere dizer: experiência de vida.

\begin{abstract}
Ganhava algum dinheiro e muita experiência de vida. Acho que isso tudo me preparou mais do que outras atividades puramente intelectuais a ser uma boa aluna de História. Sempre achei que o historiador não pode viver apenas no meio de papel velho, embora seja fundamental que ele domine e muito bem os seus instrumentos de trabalho, sobretudo os seus arquivos de documentos. ${ }^{9}$
\end{abstract}

Porém, se esperamos que ela situe sua contribuição tendo como base suas obras, ou que ela se defina como historiadora a partir delas, estamos cometendo

${ }_{9}$ Citação retirada Disponível em: http://www.revistadehistoria.com.br/secao/na-rhbn/morre-maria-yedda. Acesso: 18 ago. 2016. 
um equívoco. Sua identidade de historiadora contempla os múltiplos campos profissionais em que atuou, salientando principalmente o trabalho docente; a vida pessoal e subjetiva, ou seja, a maneira como "cuidou de si"; e a posição de um sujeito que mantém a preocupação com seu país, sua política e questões sociais. Percebemos uma memória profissional e pessoal que articula o presente e o passado, o esquecido e o rememorado, a experiência material e a subjetiva.

Apesar de aposentada, continuo dando minhas aulas na Universidade Severino Sombra (USS) em Vassouras, aqui perto do Rio, orientando pesquisa no curso de mestrado. Sou consultora da FAPERJ. De vez em quando, como já disse, me chamam para palestras, participar em banca de tese, em seminários de pesquisa, tanto no Rio como em outros estados, sobretudo Minas, onde há uma História Agrária em expansão de excelente qualidade. Como professora emérita da UFRJ, continuo em exercício, participando em cursos, seminários, bancas, etc., e cuido de mim: ando muito, faço bicicleta, hidroterapia, RPG, cuido dos gatos e da casa, e adoro cozinha. Continuo lendo meu Dante Alighieri, e, vez por outra, releio um conto do Joyce. Continuo adorando cinema e música, quanto mais moderna melhor, relembrando minha infância cearense, minha paisagem nordestina, rezando e torcendo pela grande mudança que um dia virá, num futuro sem vítimas de fome, num Brasil sem latifundiários (LINHARES 2007, p. 43).

A narrativa de Maria Yedda acerca de sua própria avaliação de "sentirse historiadora" nos revela a possibilidade de conflitarmos com a ficção e elaboração imaginária de um sujeito autor que trabalha solitariamente em seu gabinete com seus documentos. Esta é apenas uma das facetas de um trabalho que se articula com múltiplas dimensões, incluindo aquelas que atravessam o terreno dos afetos e das relações humanas. O "sentir-se historiadora" abrange também, não somente a pesquisa em si, mas projetos que envolvem a preservação de documentos e arquivos, projetos institucionais e de associações, orientação, docência e participação na vida pública. É mais que uma intelectual que desenvolve e escreve pesquisas: ela age na universidade, cria campos de discussão política, participa de grupos, constrói e amplia redes de sociabilidade e pertencimento. Todos esses movimentos, ações e experiências que ocorreram na vida não só de Maria Yeda como de outros profissionais constituem, de certa maneira, a base que fundamentou e estruturou a História como uma disciplina que possui um método de estudo que Ihe é próprio, que tem uma prática regular de leitura e análise de documentos.

A existência de um "relato de si", como vimos nas entrevistas, borram as fronteiras entre a vida do pesquisador e a suposta "neutralidade" conferida ao seu ofício. Ao pensar os atributos vinculados ao ofício do historiador e da historiadora, bem como as condições individuais e coletivas que constituem o "ser historiador" ou "ser historiadora", Certeau chama atenção para algumas tendências que ainda defendem a "ideologia atomista de uma profissão liberal que mantém a ficção do sujeito autor, deixando de acreditar que a pesquisa individual constrói a história". Os "relatos de si" que tantos outros historiadores e historiadoras forneceram em entrevistas, memoriais e depoimentos são 
interessantes no sentido de observamos a maneira como eles constroem uma reflexão de si mesmos, de seu percurso profissional e intelectual. Nesse sentido, a atenção aos registros da memória, da biografia e de uma história de vida única e singular pode ser uma importante ferramenta de análise quando se pretende investigar o ofício da nossa profissão.

\section{Vida familiar e profissional: pontos de tensionamento}

Quem é o historiador e historiadora quando faz "história?". Esta pergunta pode sugerir uma outra problematização, aquela que desloca o olhar das práticas de trabalho para a vida privada, pessoal. Nessa última seção gostaríamos de compreender como foi a experiência de lidar com dois tipos de atividades, uma pública e outra privada, que requerem, cada qual à sua maneira, dedicação e disponibilidade. Sobre esses temas, seria até mesmo pertinente perguntarmos se nossa classe profissional visualiza a articulação trabalho-família como uma questão social não só como objeto de estudos, mas como experiência individual e/ou geracional. Defendemos que certamente trata-se de uma questão social, pois a entrada das mulheres na vida pública e intelectual, tanto a partir de sua incorporação ao mercado de trabalho, como nos visíveis avanços de escolarização e na participação política, não foi acompanhada da inserção dos homens nas tarefas reprodutivas, historicamente associadas às mulheres. Com isso, sabe-se que o acesso à educação superior não foi suficiente para mudar os desequilíbrios e as desigualdades de gênero, principalmente em um espaço

1.30 ocupacional no qual a alta qualificação, a formação continuada, a produção científica e a circulação nacional e internacional são indispensáveis à ascensão na carreira.

Se por um lado direcionamos nossa análise naquilo que foi dito, por outro, devemos também refletir sobre o que não foi dito ou parcialmente dito por Maria Yedda, ou seja, em temas que ainda hoje geram dúvidas, conflitos e tensões para as mulheres que trabalham, independentemente das atividades profissionais que exercem. Trata-se de reconhecer as intersecções entre vida profissional e a vida familiar, isto é, o tensionamento entre a esfera pública e privada. Nos testemunhos de Maria Yedda e de outras pioneiras ${ }^{10}$ que contaram suas experiências de vida no meio universitário, não há menções a respeito de como elas lidaram com aspectos condizentes ao casamento, filhos, vida pessoal e familiar. Pergunta-se: aquelas que foram casadas, tiveram apoio e reconhecimento de seus maridos? Quais foram as dificuldades enfrentadas na divisão dos papéis sociais do casal? A maternidade foi um fator impeditivo no exercício de algumas atividades ou ocupação de cargos? Deixaram de realizar algum curso de pós-graduação em outro país em virtude da família? Com efeito, a articulação entre a vida pessoal com a profissisonal está ausente em seus relatos.

Isso indica um questionamento, o de que existe uma concepção permanente de que o trabalho do professor universitário, do pesquisador e, sobretudo do

10 Citamos os depoimentos de Olga Pantaleão (2003), Alice Canabrava (2003), Eulália Lobo (1992; 2007), Emília Viotti da Costa (2007), Maria Odila da Silva Dias (2007) como exemplo. 
intelectual, é algo dissociado de toda e qualquer atividade vinculada à vida doméstica e pessoal. Não se questiona, também, o quanto as experiências da vida privada impactam na carreira, na disponibilidade, no tempo dedicado à leitura e escrita, nas decisões tomadas e, por que não, na escolha dos temas pesquisados. Nesse sentido, o espaço universitário e o trabalho do historidor e da historiadora são tratados como campos neutros, nos quais não há interferência de experiências da vida pessoal.

Maria Yedda casou-se e teve filhos. No entanto, ficamos sabendo parcialmente a maneira como conciliou (ou não) a vida familiar e afetiva com a profisisonal. Em uma das entrevistas que concedeu a Mari del Priori, afirma que encontrou dificuldades com o tempo disponível para a realização de pesquisas: "Uma mulher normal como eu, com família, com filhos etc., não poderia dedicar 24 horas do dia à história. A gente tem, enfim, outras compensações na vida" (LINHARES 2006, p. 15). A historiadora casou-se com o cearense José Alves Linhares em 1947, aos 26 anos, um pouco depois que se formou. Desse relacionamento, nasceram Maria Teresa e José. Houve certa resistência na família dele, "pois não era comum a mulher casada trabalhar fora de casa. Ainda vigorava na sociedade, sobretudo nordestina, o papel da mulher para fins exclusivamente domésticos" (LINHARES 2007, p. 28). José fazia parte de uma família muito rica e tradicional, era escrivão de cartório e sobrinho do ministro e presidente do Supremo Tribunal Federal, José Linhares. Sobre o casamento, Maria Yedda relata com orgulho que:

Nosso casamento deu muito certo e fomos felizes como no conto de fadas. José tornou-se o maior incentivador e principal apoio à minha vida profisisonal nesses anos todos. No casamos em 1947 e vivemos 38 anos juntos, até ele falecer em 1985. Foi meu amigo e colaborador, orgulhoso de tudo o que eu fazia, solidário em todos os sentidos (LINHARES 2007, p. 28).

Nas entrevistas, a historiadora faz sempre questão de elogiar o marido por seu apoio. Ela recebeu incentivo profissional e financeiro de José em todas as fases de sua carreira, estando ele ao seu lado inclusive nos momentos mais difíceis, como na ditatura militar e nos embates com Eremildo Viana. Não apenas isso, mas as poucas linhas que Maria Yedda narra sobre seu marido, revelam um homem muito companheiro em relação às suas atividades, pois participava dos debates políticos e profissionais, viajava com ela, recebia muito bem seus amigos e lia seus trabalhos. Só pelo fato de Maria Yedda ter construído uma vasta sociabilidade com homens intelectuais, tecendo relações de afeto e amizade, indica o quanto José não colocou obstáculos para que ela exercesse uma das suas principais características: ser agregadora e politicamente bem relacionada. Foi ele, por exemplo, quem a incentivou a prestar o concurso para a cátedra: "Eu vivia aqui com meu marido, meus filhos, tinha uma vida doméstica muito boa, meu marido já se revelava naquele momento um colaborador de primeiríssima ordem. No fundo, foi ele quem me incentivou" (LINHARES 1992, p. 225).

Sobre os filhos e maternidade, não há menções em suas entrevistas de como os articulou com a vida profissional. Não conseguiremos responder como 
uma mulher ativa, construtiva e dona de uma sólida carreira negligenciou ou não as obrigações do lar. No entanto, ficamos sabendo um pouco sobre esse tema nos registros do historiador Francisco Carlos Teixeira, seu ex-aluno e colega de profissão:

\begin{abstract}
Do casamento teve Maria Teresa, "Teca", e José, "Zequinha"! Havia orgulho nos filhos, via-se neles, sentia por eles. Uma das maiores revoltas foi vêlos envolvidos na insidiosa e malsã campanha da imprensa golpista nos idos de março de 1964. Creio também que ambos pagaram algum preço - o preço de serem filhos de Yedda, o preço das horas roubadas, o preço de partilhá-la com todos nós, comigo, com Ciro Cardoso e principalmente com Francisco Falcon. Temos que pedir perdão por isso, perdão por tê-la tanto tempo conosco! A tudo se juntava a presença de Yonne Leite, outro motivo de orgulho de Yedda, que a via, com tudo que isso encerra, bem mais como filha do que irmã. ${ }^{11}$
\end{abstract}

Para as pioneiras que decidiram casar-se e ter filhos, foi imprescindível o apoio de seus maridos para que desenvolvessem uma vida profissional na História. Trabalhar numa universidade, conviver com intelectuais, viajar, frequentar espaços públicos como arquivos e bibliotecas, receber em casa alunos e alunas e poder dedicar o tempo para a leitura e escrita são ações que demandam compreensão e companherismo por parte de maridos e filhos. Mesmo aquelas que tiveram apoio de seus companheiros, provavelmenteenfretaram conflitos e tensões no manejo da vida profissional e doméstico-afetiva. Ainda mais no que se refere à maternidade, em que o papel atribuído às mulheres, nos ditos "anos dourados", era o de cuidar, amar e colocar os filhos em primeiro lugar.

Por fim, outro fator esteve relacionado com o fundamental apoio por parte de seu marido, foi a certeza da segurança financeira para se dedicar integralmente à pesquisa. O caso dela representa as experiências que muitos historiadores e historiadoras tiveram em relação à vida privada: no interior de seus lares, a possibilidade de poder compartilhar seus trabalhos com seus respectivos parceiros e parceiras e receber compreensão, parecem ter sido indicadores muito importantes que, direta ou indiretamente, modularam suas carreiras. No caso das historiadoras pioneiras, se a união com companheiros que tinham interesse em suas carreiras foi fundamental, há também de se considerar que elas não estavam integradas inteiramente em uma cultura doméstica tradicional.

\title{
Referências bibliográficas
}

ARFUCH, Leonor. O espaço biográfico: dilemas da subjetividade contemporânea. Rio de Janeiro: EdUERJ, 2010.

BALDEZ, Coryntho. Entrevista: Maria Yedda Linhares. Jornal da UFRJ, ano 4, n. $40,2008$. 
BLAY, Eva Alterman; LANG, Alice Beatriz. Mulheres na USP: horizontes que se abrem. São Paulo. Associação Editorial Humanitas, 2004.

CAPELATO, M. H.; GLEZER, R.; FERLINI, V. L. A. Escola Uspiana de História. Estudos Avançados, v. 8, n. 22, 1994.

CERTEAU, Michel de. A escrita da História. Rio de Janeiro: Forense, 2011.

FÁVERO, Maria de Lourdes de A. A universidade no Brasil: das origens à reforma universitárias de 1968. Educar. Curitiba: Ed. UFPR, n. 28, 2006.

FERREIRA, Marieta de Moraes. Uma entrevista com Maria Yedda Linhares. Estudos Históricos, v. 5, n. 10, 1992.

A História como ofício: a contribuição de um campo disciplinar. Rio de Janeiro: Ed. FGV, 2013.

MORAES, José Geraldo; REGO, José Marcio. Maria Yedda Linhares. In:

Conversa com historiadores brasileiros. São Paulo: Ed. 34, 2002.

PERROT, Michelle. As mulheres ou os silêncios da história. Bauru: EDUSC, 2005.

PINSKY, Carla Bassanezi. Mulheres dos anos dourados. São Paulo: Contexto, 2014.

PRIORI, Mari del. Maria Yedda Linhares: por uma história documentada. Revista do Arquivo Público Mineiro, p. 15, 2006.

SCHMIDT, Benito. Luz e papel, realidade e imaginação: as biografias na história, no jornalismo, na literatura e no cinema. In: SCHMIDT, Benito (Org.). 0 biográfico: perspectivas interdisciplinares. Santa Cruz do Sul: UNISC, 2000.

SILVA, Francisco Carlos; MATTOS, Hebe Maria; FRAGOSO, João (Org.). Escritos sobre história e educação: homenagem a Maria Yedda Linhares. Rio de Janeiro: Mauad, 2001.

SMITH, Bonnie. Gênero e História: homens, mulheres e a prática histórica. Bauru: EDUSC.

ZECHLINSKI, Beatriz Polidori. Três autoras francesas e a cultura escrita no século XVII: gênero e sociabilidades. Tese (Doutorado em História) - Programa de Pós-Graduação em História, Setor de Ciências Humanas, Letras e Artes da Universidade Federal do Paraná, Curitiba, 2012. 